\title{
Resistance to early-life stress in mice: effects of genetic background and stress duration
}

\author{
Hélène M. Savignac ${ }^{1,2}$, Timothy G. Dinan ${ }^{1,3}$ and John F. Cryan ${ }^{1,2,4 *}$ \\ 1 Laboratory of Neurogastroenterology, Alimentary Pharmabiotic Centre, University College Cork, Cork, Ireland \\ 2 School of Pharmacy, University College Cork, Cork, Ireland \\ ${ }^{3}$ Department of Psychiatry, University College Cork, Cork, Ireland \\ ${ }_{4}^{4}$ Department of Pharmacology and Therapeutics, University College Cork, Cork, Ireland
}

\section{Edited by:}

Riccardo Brambilla, San Raffaele

Scientific Institute and University, Italy

\section{Reviewed by:}

Mathias V. Schmidt, Max Planck Institute of Psychiatry, Germany René Hurlemann, University of Bonn, Germany

\section{${ }^{*}$ Correspondence:}

John F. Cryan, Department of

Pharmacology and Therapeutics,

School of Pharmacy, University College

Cork, College Road, Cork, Ireland.

e-mail:j.cryan@ucc.ie
Early-life stress can induce marked behavioral and physiological impairments in adulthood including cognitive deficits, depression, anxiety, and gastrointestinal dysfunction. Although robust rat models of early-life stress exist there are few established effective paradigms in the mouse. Genetic background and protocol parameters used are two critical variables in such model development. Thus we investigated the impact of two different early-life stress protocols in two commonly used inbred mouse strains. C57BL/6 and innately anxious BALB/c male mice were maternally deprived $3 \mathrm{~h}$ daily, either from postnatal day 1 to 14 (protocol 1) or 6 to 10 (protocol 2). Animals were assessed in adulthood for cognitive performance (spontaneous alternation behavior test), anxiety [open-field, light/dark box (L/DB), and elevated plus maze (EPM) tests], and depression-related behaviors (forced swim test) in addition to stress-sensitive physiological changes. Overall, the results showed that early-life stressed mice from both strains displayed good cognitive ability and no elevations in anxiety. However, paradoxical changes occurred in C57BL/6 mice as the longer protocol (protocol 1) decreased anxiety in the L/DB and increased exploration in the EPM. In BALB/c mice there were also limited effects of maternal separation with both separation protocols inducing reductions in stress-induced defecation and protocol 1 reducing the colon length. These data suggest that, independent of stress duration, mice from both strains were on the whole resilient to the maladaptive effects of early-life stress. Thus maternal separation models of brain-gut axis dysfunction should rely on either different stressor protocols or other strains of mice.

Keywords: maternal separation, stress, genetics impact, resistance, behavior, mice, anxiety

\section{INTRODUCTION}

Early-life stress has been implicated in the development of longlasting behavioral and physiological alterations such as anxiety, depression, and cognitive impairments in adulthood (Carpenter et al., 2007; Drake et al., 2007; Lazinski et al., 2008; Wachs, 2009; Dinan et al., 2010). Notably, a link has been established between early-life trauma and the development of irritable bowel syndrome (IBS), a common and debilitating functional gastrointestinal (GI) disorder which is highly co-morbid with psychiatric diseases (Bair et al., 2003; Mertz, 2003; Dinan, 2005; North et al., 2007; Wood, 2007; Eriksson et al., 2008; O’Mahony et al., 2009). However, independent of the intensity or nature of the event, some people are naturally resistant to stressful events, suggesting that both genetic and environmental factors play a key role in the modulation of the stress response and susceptibility (Charney and Manji, 2004; Levine, 2005; Wurtman, 2005; Hotoleanu et al., 2008). Yet, the exact mechanisms underlying the likelihood to develop stress-related disorders remain poorly understood (Krishnan and Nestler, 2008; Mayer et al., 2008; McKernan et al., 2009).

Animal models of psychiatric diseases have considerably contributed to our understanding of stress-induced psychopathologies over the past decades (Cryan and Holmes, 2005; Anisman et al., 2008; O'Mahony et al., 2011). One well-established model in rats is the maternal separation (MS) paradigm, for which rodent pups are separated each day from their mother for varying lengths of time during the postnatal period (Ladd et al., 2004; Veenema et al., 2006; Weaver et al., 2007; Schmidt et al., 2011). MS has been reported to induce long-lasting behavioral and physiological changes that can persist into adulthood (Pryce et al., 2005; Macri and Wurbel, 2006; O'Mahony et al., 2009; O'Malley et al., 2010; Uhelski and Fuchs, 2010). Most of these MS protocols have produced reproducible results in rats, however, attempts to replicate these findings in the mouse have been less than successful, notably due to the difficulty to induce consistent and robust behavioral alterations measurable in adulthood (Millstein and Holmes, 2007; O'Mahony et al., 2011). Given the importance of mice in behavioral genetics research there is a clear need to develop robust mouse models of MS (Jacobson and Cryan, 2007).

Maternal separation effects on anxiety behavior in adulthood are commonly assessed with widely used tasks such as the light/ dark box (L/DB), the open-field (OF), or the elevated plus maze (EPM) for anxiety (Romeo et al., 2003; Cryan and Holmes, 2005; Millstein and Holmes, 2007). With regard to depression, tasks that are shown to be sensitive to the behavioral effects of antidepressants such as the forced swim test (FST) are widely used (Cryan et al., 2005). It should be acknowledged that whilst such 
tasks are robust behavioral screening paradigms, they have limited face, and construct validity as models of the disease per se (Jacobson and Cryan, 2007; Pryce and Seifritz, 2011). Nonetheless, increases in immobility in the FST have been shown to be sensitive to various factors that influence or are altered by depression in humans, including genetic predisposition, previous exposure to stress, changes in food intake, alterations in sleep architecture, and drug-withdrawal-induced anhedonia and psychostimulant withdrawal (Cryan and Holmes, 2005).

Choice of separation protocol is one of the main variables in developing rodent models of early-life stress. Increasing evidence suggests that specific durations of MS or genetic background may impact the development of susceptibility to MS-induced changes in adulthood in mice (Millstein and Holmes, 2007; O'Mahony et al., 2011; Schmidt et al., 2011). Thus it has been demonstrated that chronic daily separation of at least $180 \mathrm{~min}$, from postnatal day (P) 0 to 14 impacts on anxiety, as assessed by the OF and EPM (Romeo et al., 2003; Millstein and Holmes, 2007). On the other hand, MacQueen et al. (2003) have demonstrated a longer chronic separation period from P4 to P21 increased immobility in the FST in C57BL/6 mice. Moreover, higher exploration in the EPM has also been reported in CD-1 mice using a P2-P14 separation protocol (Venerosi et al., 2003), while no change was found in male C57BL/6NCrlBR in anxiety-related behavior following a 180-min chronic separation from P0 to P9 (Parfitt et al., 2004). Further, chronic 15-min separation for instance from P1 to 14 , is reported to yield opposite effects on emotion-related behaviors in both NMRI and outbred albino mice, showing no change or a decrease in anxiety (Cabib et al., 1993; Moles et al., 2004). These shorter separation periods may imitate the natural rearing situation for the rats, where the mother leaves her pups for short periods to gather food (Oreland et al., 2009). Therefore this paradigm may not be useful for the study of disorders that are induced by early-life stress such as IBS. Regarding gender, overall, male mice appear to be more affected by MS than female (Millstein and Holmes, 2007).

In the present study we sought to behaviorally validate a robust mouse model of early-life stress for assessing psychiatric and brain-gut axis dysfunction. Thus we assessed the behavioral and physiological impact of two different MS paradigms differing both in the time of initiation of the separation procedure and in their length in term of days of separation, in two inbred mouse strains which differ in their stress susceptibility, the innately anxious $\mathrm{BALB} / \mathrm{c}$, and the commonly used C57BL/6 strain (Belzung and Griebel, 2001; Jacobson and Cryan, 2007; Millstein and Holmes, 2007). Indeed, BALB/c mice have been proposed to be a model of pathological anxiety (Belzung and Griebel, 2001) and have been shown to display higher anxiety levels than C57BL/6 mice (O'Mahony et al., 2010). Therefore, we expected BALB/c mice to be more sensitive to early-life stress than C57BL/6 animals. The differences between the two protocols we used lied on the fact that BALB/c mothers are known to display less maternal care toward their pups than C57BL/6 mothers (Romeo et al., 2003; Priebe et al., 2005) and short daily 15-min ("handling") MS induces mothers to compensate on maternal care levels to their pups at reunion, that may result in lower anxiety behavior in adulthood (Millstein and Holmes, 2007; Schmidt et al., 2011).
Therefore, our hypothesis was that a 3 -h, rather than $15-\mathrm{min}$, daily separation, would be more likely to induce stress at an adult stage (Veenema et al., 2007), in both strains, but also more specifically so in BALB/c mice. Also, as the mother-pup dyad may acclimatize to daily separations for a protocol starting at P1 and induce mothers to overcompensate for separation, we compared a long separation protocol from P1 to 14 (Veenema et al., 2007) with a shorter separation protocol from P6 to 10 (Groer et al., 2002), assuming that the second protocol would be more likely to disturb mother-pup interactions and induce stress than the longer protocol.

\section{MATERIALS AND METHODS ANIMALS}

A total of 15 male and 15 female BALB/cOlaHsd and C57BL/6OlaHsd mice, 7 weeks old, were purchased from Harlan UK Laboratories. Mice were allowed to habituate for 10 days to the animal facility prior to mating. Each male was housed with one female, maintained in standard plastic mouse cages $(22 \mathrm{~cm} \times 16 \mathrm{~cm} \times 14 \mathrm{~cm})$ and kept under standard housing conditions (room temperature $22 \pm 1^{\circ} \mathrm{C}$, $55 \pm 5 \%$ humidity, fed ad libitum), in a 12-h light/dark cycle (lights on 7 a.m. to 7 p.m.). Males were removed from the dam at gestationday 15 to habituate females to single-housing before giving birth. Following weaning, at P21, the female pups were culled and males were used for behavioral analysis in adulthood. This was done so as not to add extra stress to the mothers during the separation period. Offspring were group-housed two to four per cage. Mice underwent behavioral procedures at adult stage, 8 weeks of age. All experiments were conducted in accordance with the European Directive 86/609/EEC, the Recommendation 2007/526/65/EC and approved by the Animal Experimentation Ethics Committee of University College Cork.

\section{MATERNAL SEPARATION PROCEDURE}

Litters were randomly assigned to control or stress groups at birth. Mouse pups underwent two distinct procedures of daily 180-min separation (see Figure 1). Protocol 1 pups were separated from the mother from P1 to P14 (long protocol) whereas protocol 2 pups were separated from P6 to 10 (short protocol). Control group was left undisturbed in their home cage during the separations experiments ("animal-facility-reared group, AFR") except for routine cage changes.

Experiments were conducted during the light phase between 9 and 12 a.m. All litters were brought from the breeding room into a different experimental room. Pups were individually separated without bedding and placed in an open plastic container with a heating blanket underneath. This type of isolation separation has been suggested to increase stress severity (Anisman et al., 1998; Millstein and Holmes, 2007). Mothers were then removed from the experimental room to avoid ultrasound communication with the pups. After the 3-h-separation, pups were returned to their mothers. Control pups were also moved to experimental room but remained undisturbed with their mother, without handling as daily and brief handling may decrease anxiety behavior at adult stage (Cabib et al., 1993; Parfitt et al., 2004). Following MS procedure, pups remained undisturbed until weaning at P21. Maternal care was not assessed in this study, as it is already extensively described in 


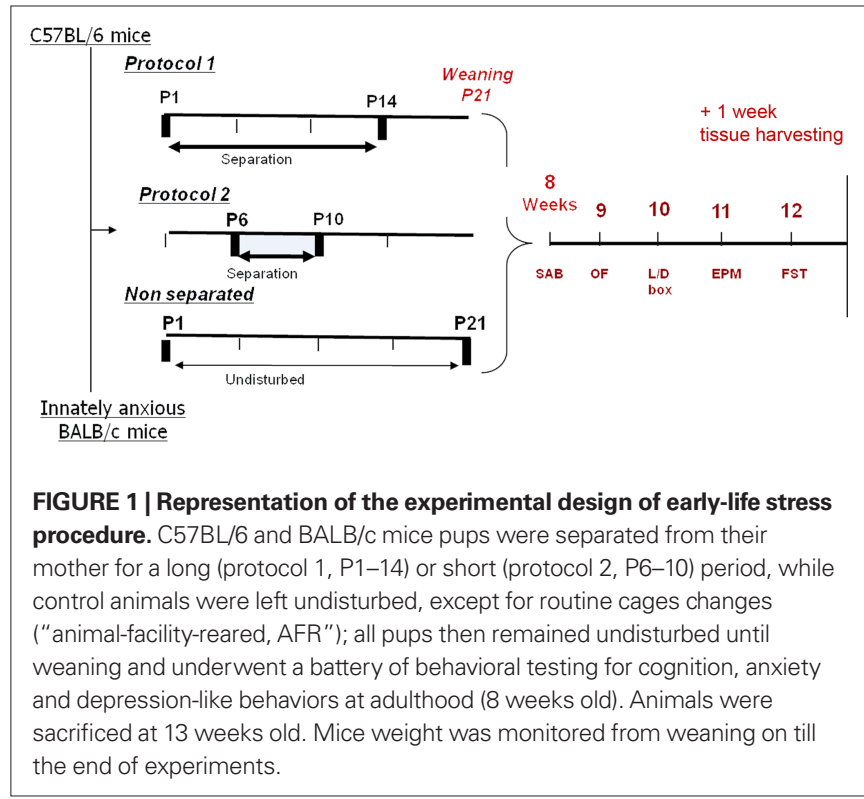

literature for these mouse strains (Anisman et al., 1998; Calatayud and Belzung, 2001; Caldji et al., 2004; Priebe et al., 2005; Millstein and Holmes, 2007). Experimental groups were generated from at least four different litters.

\section{EXPERIMENTAL DESIGN}

At adulthood (8 weeks old), mice underwent a battery of behavioral tests (Figure 1) over a period of 5 weeks. Each behavioral test was conducted 1 week apart and was conducted in sequence from the least to the most stressful test (Crawley, 2008). Mice were also weighed weekly at this time. At 13 weeks old, animals were sacrificed by cervical dislocation and samples collected.

\section{BEHAVIORAL TESTING}

\section{Conditions common to all tests}

Lighting conditions were similar for all experiments, with room lighting (100 lux at $1 \mathrm{~m}$ above floor), except for the EPM which was conducted in dim light $(20 \pm 2$ lux $)$. For all procedures, animals were brought to the room at least $1 \mathrm{~h}$ prior to testing. Animals of the same litter were tested one at a time. An effect of group order on behavioral outcome within litter was considered, which may occur in studies with group-housed animals (Millstein and Holmes, 2007; Veenema et al., 2007); however, to counterbalance this effect, animals of all groups were tested in a random fashion and under the same conditions (Millstein and Holmes, 2007). All experiments were conducted between 9 a.m. and 2 p.m. All apparatus were cleaned between animals with $70 \%$ ethanol to remove odors. The order of testing was random regarding litters and groups, with an experimenter blind to conditions. Pups tested in behavioral tasks were from at least three different litters for each group, with each of them having equivalent and counterbalanced litter size. As a result, mean values were calculated from all pups irrespective of litters. For C57BL/6 control group $n=14$, protocol $1 n=19$, protocol 2 $n=11 ; \mathrm{BALB} / \mathrm{c}$ control group $n=13$, protocol $1 n=11$, protocol $2 n=13$.

\section{Spontaneous alternation behavior}

At 8 weeks old, mice were tested in the spontaneous alternation behavior (SAB) test, which assesses working memory (Lalonde, 2002). The task was carried out as described previously (Jacobson et al., 2007b). The maze consisted of a black plastic 3-arm Y-maze $(15 \mathrm{~cm} \times 5 \mathrm{~cm} \times 10 \mathrm{~cm}, L \times W \times H)$. Mice were individually placed in one of the 3 arms and allowed 5-min free exploration. The sequence of visited arms was noted. At the end of the trial, mice were placed back in their home cage with littermates. The two main parameters measured were the number of entries as an index of locomotor activity and the percentage alternation as a measure of working memory.

\section{Open-field}

At 9 weeks old, mice were tested in the OF for anxiety-related behavior. The apparatus was a gray plastic open arena without any bed$\operatorname{ding}(40 \mathrm{~cm} \times 30 \mathrm{~cm} \times 25 \mathrm{~cm}, L \times W \times H)$. Mice were allowed 10-min free exploration in the box, behavior was recorded using a video camera and the number of fecal pellets in the arena was counted as an index of anxiety (Barone et al., 2008). For data analysis, the arena was divided into 16 equal areas with the 4 central ones constituting the central zone. The percentage of time spent in the center was considered an inverse score for anxiety-like behavior, the number of squares crossed was counted as an index of locomotor activity, and rearing numbers were assessed for stereotypic behavior. To assess if differences between groups became apparent over time (van Heerden et al., 2010), data were also analyzed across two different time-periods: the first and last 5-min block. At the end of the trial, mice were placed back in their home cage with littermates.

\section{Light/dark box}

At 10 weeks old, mice were tested in the L/DB test for anxiety as previously described (O'Mahony et al., 2010). The apparatus was a plexiglas enclosure $(44 \mathrm{~cm} \times 21 \mathrm{~cm} \times 21 \mathrm{~cm}, L \times W \times H)$ separated into two compartments, a large and brightly lit open area (transparent), and a smaller, dark close and safe part ( $14 \mathrm{~cm}$ long), comprising a small opening $(10 \mathrm{~cm} \times 5 \mathrm{~cm})$ to allow transitions between the two parts. Mice were individually placed into the light part, and allowed 10-min free exploration. The number of transitions between the two parts, latency to enter the dark part and the time spent in the light part were manually scored post test using the recorded videos. At the end of the trial, mice were placed back into their home cage with littermates.

\section{Elevated plus maze}

At 11 weeks old, mice were tested in the EPM test of anxiety which was carried out essentially as described previously (Jacobson et al., 2007a). The apparatus was made of an elevated cross plastic maze ( $1 \mathrm{~m}$ from the floor), comprising two open and two closed arms ( $50 \mathrm{~cm} \times 5 \mathrm{~cm} \times 15 \mathrm{~cm}$ walls), respectively constituting the fearful and safe areas. Mice were individually placed into the center of the maze facing an open arm to avoid direct entrance into a closed arm and leave the mice free choice for open or close arm and were allowed 5-min free exploration. The time spent in each arm, and the number of entries, were scored (entrance in one arm being defined as all four paws inside the arm). At the end of the trial, mice were placed back into their home cage with littermates. 


\section{Forced swim test}

At 12 weeks old, depression-like behavior in the FST was assessed as previously described (Cryan et al., 2001). Mice were individually placed in a transparent plexiglas cylinder $(24 \mathrm{~cm}$ height $\times 21 \mathrm{~cm}$ diameter), containing $15 \mathrm{~cm}$-depth water maintained at room temperature $\left(22 \pm 1^{\circ} \mathrm{C}\right)$ for a single 6 -min trial. Water was changed between each mouse. The latency to immobility was monitored and the last $4 \mathrm{~min}$ were scored for the total time of immobility (Cryan et al., 2002; Jacobson and Cryan, 2007). Immobility was defined as the total absence of movement except slight motions to maintain the head above the water. At the end of the trial, mice were dried and placed back into their home cage with littermates.

\section{TISSUE HARVESTING}

Mice were sacrificed by cervical dislocation and decapitated at 13 weeks old; all sampling occurred between 8:30 a.m. and 1:00 p.m. The colon was removed, mechanically cleaned and its length was measured ( $0.1 \mathrm{~cm}$ precision) as an index of colonic inflammation, as colon length reductions have been associated with the occurrence of an inflammatory process (Reber et al., 2006). Body weight evolution from weaning on, thymus and spleen weight were also investigated as chronic social stress is often associated with body weight change, thymus hypotrophy, and splenomegaly (Bartolomucci et al., 2005; Engler et al., 2005; Reber et al., 2007).

\section{STATISTICAL ANALYSIS}

Two-way ANOVA (factors: MS and time) was used to assess bodyweight data and also behavior and tissue data (factors: MS protocol and strain). The normal distribution of the data was assessed with a Shapiro-Wilk test. Where relevant, post hoc analysis was conducted using Fisher's post hoc test. Statistical significance was set at $p<0.05$. Data are expressed as mean \pm SEM.

\section{RESULTS}

\section{MATERNAL SEPARATION EFFECTS ON BODYWEIGHT}

Maternal separation had an overall effect on weight in C57BL/6 mice (Figure 2A). Indeed, two-way ANOVA revealed an effect of MS $[F(2,466)=18.17, p<0.0001]$ and time, from weaning until 13 weeks old $[F(10,466)=526.21, p<0.0001]$ but there was no
MS $\times$ time interaction $[F(20,466)=1.59, p=0.051]$. Post hoc analysis further revealed that protocol $1 \mathrm{MS}$ mice had lower bodyweight than control group on week $4(p<0.001)$. Two-way ANOVA also showed an overall MS effect on bodyweight in BALB/c mice (Figure 2B), from weaning until 13 weeks old $[F(2,371)=19.11, p<0.0001]$, as well as a time effect $[F(10,371)=461.26, p<0.0001]$, although no difference raised on post hoc analysis ( $p>0.05$ all days); however there was no $\mathrm{MS} \times$ time interaction $[F(20,371)=0.74, p=0.781]$.

\section{MATERNAL SEPARATION EFFECTS ON BEHAVIOR Spontaneous alternation behavior in Y-maze}

Neither of the two MS protocols produced any cognitive impairment (Figure 3A). Indeed, two-way ANOVA revealed there was no MS effect $[F(2,75)=1.18, p=0.313]$, or MS $\times$ strain interaction $[F(2,75)=1.86, p=0.163]$ in the $\%$ alternation. However, there was an overall strain effect $[F(1,75)=8.04, p=0.0059]$. Post hoc analysis revealed that MS protocol $1 \mathrm{C} 57 \mathrm{BL} / 6$ alternated more than their respective $\mathrm{BALB} / \mathrm{c}$ animals with no other difference between strains or groups (C57BL/6 control vs. protocol 1, $p=0.773$; control vs. protocol 2, $p=0.474 ; \mathrm{BALB} / \mathrm{c}$ control vs. protocol $1, p=0.121$; control vs. protocol 2, $p=0.536$; C57BL/6 vs. BALB/c, control, $p=0.102$; protocol $1, p=0.030$; protocol $2, p=1.00)$.

Two-way ANOVA showed there was also no effect of MS on locomotor activity (Figure 3B), as assessed by the number of entries in the three arms $[F(2,75)=1.12, p=0.332]$; there was also no $\mathrm{MS} \times$ strain interaction $[F(2,75)=0.62, p=0.539]$. However, there was an overall strain effect $[F(1,75)=4.77, p=0.0321]$, but further post hoc analysis did not reveal any significant difference between groups (C57BL/ 6 control vs. protocol $1, p=0.232$; control vs. protocol 2, $p=0.482 ; \mathrm{BALB} / \mathrm{c}$ control vs. protocol $1, p=0.943$; control vs. protocol 2, $p=0.695 ; \mathrm{C} 57 \mathrm{BL} / 6$ vs. $\mathrm{BALB} / \mathrm{c}$, control, $p=0.123$; protocol $1, p=0.697$; protocol $2, p=0.078$ ).

This strain effect may indicate that overall $\mathrm{BALB} / \mathrm{c}$ mice alternated and moved less than C57BL/6 mice.

\section{Open-field behavior/locomotor activity}

Maternal separation had no effect in any of the measured parameters in either of the two strains over a 10-min session (Table 1). Indeed, two-way ANOVA revealed there was no MS effect in the

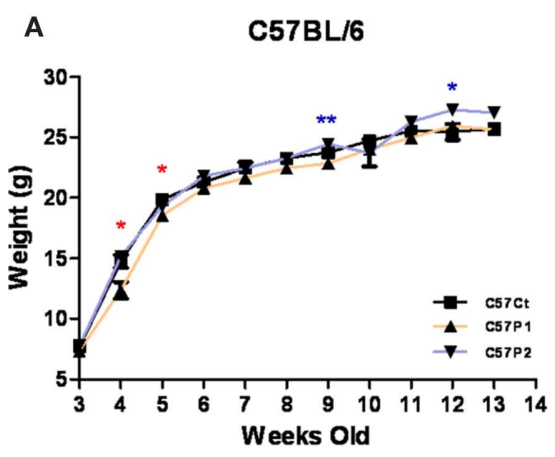

FIGURE 2 | Effect of MS on bodyweight evolution. MS had an overall effect in C57BL/6 (A), but not BALB/c (B) mice, over time, although protocol differences only rose for an isolated time-point, at 4 weeks old (C57BL/6 protocol

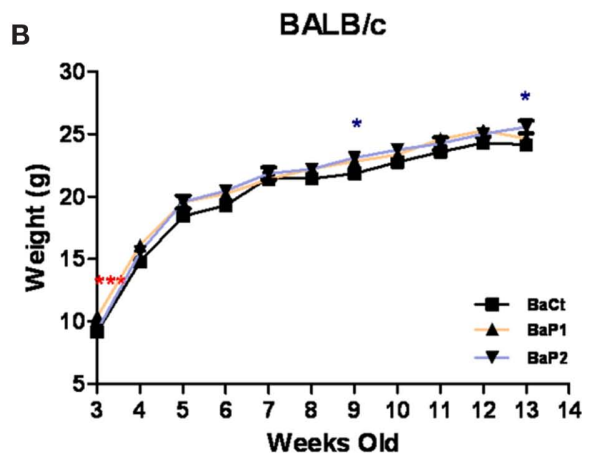

$1<$ controls). $n=11-19$ per strain per stress condition. Black " $\mathrm{Ct}$," control AFR groups; white "P1," protocol 1; blue "P2," protocol 2 ; ${ }^{* * *} p<0.001$, stress vs. control groups. Data expressed as means \pm SEM 

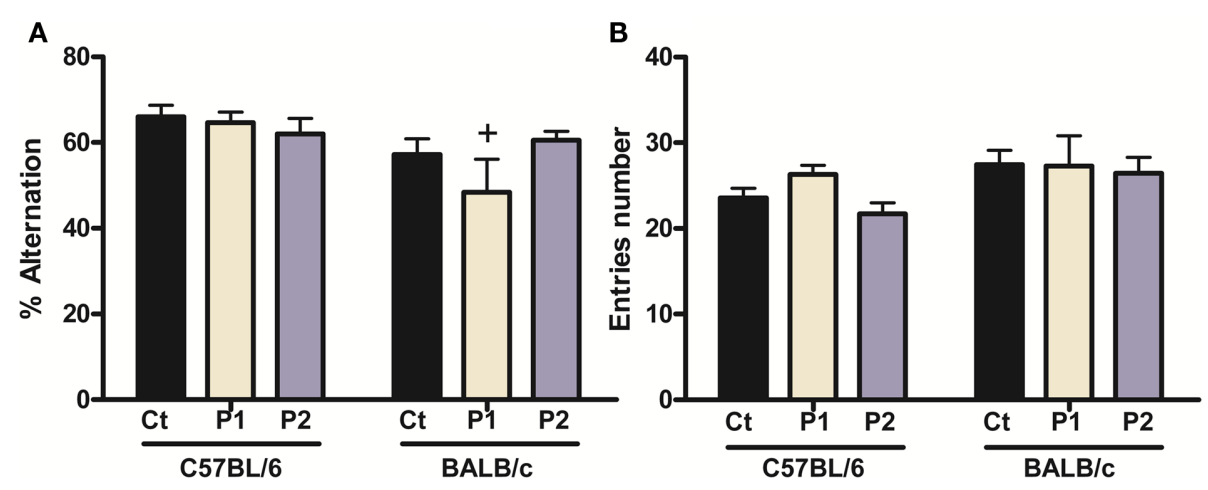

FIGURE 3 | Effect of MS on spontaneous altemation behavior. MS had no effect in either strain on \% alternation (A) or entries number [locomotor activity indice, (B)] However, there was an overall strain effect for both parameters with protocol 1
C57BL/6 mice alternating more than protocol 1 BALB/c mice. $n=11-19$ per strain per stress condition. Data expressed as means \pm SEM. Black "Ct," control AFR groups; white "P1," protocol 1; blue "P2," protocol 2; ${ }^{+} p<0.05$, C57BL/6 vs. BALB/c mice.

Table 1 | Effect of MS on behavior in the open-field test by 5-min blocks.

\begin{tabular}{|c|c|c|c|c|c|c|c|}
\hline \multirow[t]{2}{*}{ Parameter } & \multirow{2}{*}{$\begin{array}{l}\text { Time } \\
\text { (minute) }\end{array}$} & \multicolumn{3}{|c|}{ C57BL/6 } & \multicolumn{3}{|c|}{ BALB/c } \\
\hline & & Control & Protocol 1 & Protocol 2 & Control & Protocol 1 & Protocol 2 \\
\hline \multirow[t]{3}{*}{$\%$ Time center } & $0-5$ & $6.5 \pm 1.1$ & $10.4 \pm 1.8$ & $10.8 \pm 2.1$ & $5.9 \pm 1.6$ & $4.06 \pm 1.1^{++}$ & $7.24 \pm 1.6$ \\
\hline & $5-10$ & $12.1 \pm 1.5$ & $13.2 \pm 1.8$ & $12.2 \pm 2.3$ & $7.9 \pm 1.5$ & $12.55 \pm 2.7$ & $10.6 \pm 1.6$ \\
\hline & 10 & $9.3 \pm 1.0$ & $11.8 \pm 1.6$ & $11.5 \pm 1.8$ & $6.9 \pm 1.3$ & $8.3 \pm 1.6$ & $8.9 \pm 1.3$ \\
\hline & $5-10$ & $116.4 \pm 4.4$ & $116.3 \pm 5.2$ & $109.3 \pm 9.0$ & $117.1 \pm 7.5$ & $107.5 \pm 7.7$ & $113.7 \pm 4.2$ \\
\hline & 10 & $246.2 \pm 9.7$ & $257.2 \pm 13.3$ & $239.8 \pm 16.4$ & $236.7 \pm 17.0$ & $224.7 \pm 21.3$ & $235.8 \pm 9.7$ \\
\hline \multirow[t]{3}{*}{ Rearing number } & $0-5$ & $42.5 \pm 3.1$ & $53.8 \pm 4.2$ & $53.2 \pm 4.5$ & $35 \pm 6.9$ & $36.4 \pm 6.7^{+}$ & $44.7 \pm 7.5$ \\
\hline & $5-10$ & $52.6 \pm 2.9$ & $55.8 \pm 2.4$ & $55.5 \pm 4.8$ & $56.4 \pm 6.3$ & $54.8 \pm 6.2$ & $66.6 \pm 4.1$ \\
\hline & 10 & $95.1 \pm 5.0$ & $109.7 \pm 5.9$ & $108.7 \pm 8.9$ & $91.4 \pm 11.9$ & $91.2 \pm 11.5$ & $111.3 \pm 10.9$ \\
\hline
\end{tabular}

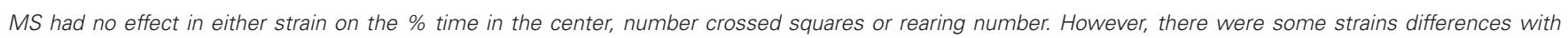

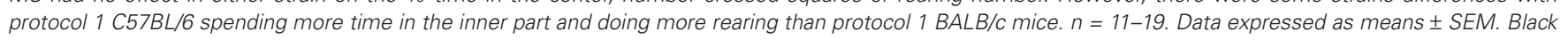
"Ct," control AFR groups; white "P1," protocol 1; blue "P2," protocol 2. ${ }^{+} p<0.05,{ }^{++} p<0.01, C 57 B L / 6$ vs. BALB/C mice.

percentage of time spent in the center of the arena $[F(2,75)=1.24$, $p=0.29]$ or $\mathrm{MS} \times$ strain interaction $[F(2,75)=0.08, p=0.92]$. However, there was an overall strain effect $[F(1,75)=5.29$, $p=0.024]$, but further post hoc analysis did not reveal any significant difference between MS groups or strains (C57BL/6 control vs. protocol 1, $p=0.194$; control vs. protocol 2, $p=0.318 ; \mathrm{BALB} / \mathrm{c}$ control vs. protocol 1, $p=0.528$; control vs. protocol 2, $p=0.347$; C57BL/6 vs. BALB/c, control, $p=0.256$; protocol $1, p=0.094$; protocol 2, $p=0.25$ ).

When analyzing the locomotor activity (number of squares crossed), two-way ANOVA revealed there was no MS effect $[F(2,75)=0.03, p=0.97], \mathrm{MS} \times$ strain interaction $[F(2,75)=0.52$, $p=0.59]$, or strain effect $[F(1,75)=1.59, p=0.211]$.

Finally, for the number of rearing, two-way ANOVA did not reveal any $\mathrm{MS}$ effect $[F(2,75)=1.65, p=0.20]$, MS $\times$ strain interaction $[F(2,75)=0.72, p=0.49]$, or strain effect $[F(1,75)=0.78$, $p=0.381]$.

The analysis was further split into the first and the last $5 \mathrm{~min}$ to investigate if temporal differences did arise over time (Table 1). For the time spent in the center of the arena during the first $5 \mathrm{~min}$, two-way ANOVA did not reveal any MS effect $[F(2,75)=1.45$, $p=0.24]$ or $\mathrm{MS} \times$ strain interaction $[F(2,75)=1.53, p=0.22]$; however, there was a strain effect $[F(1,75)=6.60, p=0.012]$. Post hoc analysis further revealed that protocol $1 \mathrm{MS}$ C57BL/6 mice spent significantly more time in the center of the arena than BALB/c mice $(p=0.007)$, but there was no difference between the other groups (C57BL/6 control vs. protocol 1, $p=0.07$; control vs. protocol 2, $p=0.076 ; \mathrm{BALB} / \mathrm{c}$ control vs. protocol $1, p=0.47$; control vs. protocol 2, $p=0.563$; C57BL/ 6 vs. BALB/c, control, $p=0.795$; protocol $2, p=0.15)$. For the last $5 \mathrm{~min}$, two-way ANOVA did not show any MS effect $[F(2,75)=1.15, p=0.32]$, MS $\times$ strain interaction $[F(2,75)=0.46, p=0.63]$, or no strain effect $[F(1,75)=1.85$, $p=0.178]$.

For the number of squares crossed during the first $5 \mathrm{~min}$, two-way ANOVA did not highlight any MS effect $[F(2,75)=0.1$, $p=0.91], \mathrm{MS} \times$ strain interaction $[F(2,75)=0.32, p=0.72]$, or strain effect $[F(1,75)=2.75, p=0.101]$. For the last 5 min, two-way ANOVA also did not show any MS effect $[F(2,75)=0.43, p=0.65]$, MS $\times$ strain interaction $[F(2,75)=0.58, p=0.56]$, or strain effect $[F(1,75)=0.05, p=0.819]$. 
Regarding the number of rearings during the first $5 \mathrm{~min}$, two-way ANOVA did not show any MS effect $[F(2,75)=1.63, p=0.20]$ or MS $\times$ strain interaction $[F(2,75)=0.49, p=0.61]$; however, there was a strain effect $[F(1,75)=5.86, p=0.018]$. Post hoc analysis further revealed protocol $1 \mathrm{MS}$ C57BL/6 mice displayed significantly more rearing than $\mathrm{BALB} / \mathrm{c}$ mice $(p=0.027)$, but there was no difference between the other groups (C57BL/6 control vs. protocol $1, p=0.118$; control vs. protocol $2, p=0.197$; BALB/c control vs. protocol 1, $p=0.871$; control vs. protocol 2, $p=0.229$; C57BL/6 vs. $\mathrm{BALB} / \mathrm{c}$, control, $p=0.343$; protocol $2, p=0.313)$. For the last $5 \mathrm{~min}$, two-way ANOVA did not show any MS effect $[F(2,75)=1.24$, $p=0.30], \mathrm{MS} \times$ strain interaction $[F(2,75)=0.92, p=0.40]$, or strain effect $[F(1,75)=1.63, p=0.205]$.

As a result, C57BL/6 mice showed some evidence of lower anxiety-related behavior than BALB/c mice across time in the $\mathrm{OF}$ test, although their overall locomotor activity and exploration did not differ.

\section{Elevated plus maze}

Maternal separation had an effect on anxiety behavior displayed by $\mathrm{C} 57 \mathrm{BL} / 6$ mice in the EPM, but no effect in BALB/c mice (Figure 4). Indeed, for the $\%$ time spent in the open arms (Figure 4A), two-way ANOVA showed there was no overall MS effect $[F(2,75)=2.09$; $p=0.131]$ and no $\mathrm{MS} \times$ strain interaction $[F(2,75)=1.031$; $p=0.362]$; however, there was a strain effect $[F(1,75)=18.62$; $p<0.0001]$. Post hoc analysis further revealed that C57BL/6 mice of both MS protocols spent more time in the open arms than non-separated control animals (protocol 1, $p=0.048$; protocol 2, $p=0.025$ ). Also, post hoc test showed C57BL/6 mice of both MS protocols spent more time in the open arms than their respective MS BALB/c mice (protocol 1, $p=0.005$; protocol 2, $p=0.002$ ), but there was no difference between C57BL/6 and BALB/c control animals $(p=0.174)$.

Regarding the \% entries in the open arms (Figure 4B), two-way ANOVA indicated there was no MS effect $[F(2,75)=2.24 ; p=0.113]$; however, there was a MS $\times$ strain interaction $[F(2,75)=4.05 ; p=0.021]$ and a strain effect $[F(1,75)=24.30 ; p<0.0001]$. Post hoc analysis revealed all MS C57BL/6 mice displayed higher \% entries than control animals (protocol 1, $p=0.001$; protocol 2, $p=0.005$ ), whereas there was no difference for BALB/c animals (control vs. protocol 1, $p=0.755$; control vs. protocol $2, p=0.567)$. Post hoc test also showed $\mathrm{C} 57 \mathrm{BL} / 6$ mice of both MS protocols displayed higher \% entries than their respective MS BALB/c mice (both MS protocols, $p<0.0001$ ).

To assess if this was due to a difference in locomotor activity, the total number of entries was monitored (Figure 5C). Two-way ANOVA showed there was no overall MS effect $[F(2,75)=1.25$; $p=0.293], \mathrm{MS} \times$ strain interaction $[F(2,75)=1.28 ; p=0.285]$, or strain effect $[F(1,75)=0.01 ; p=0.977]$.

Overall, these data suggest that MS induced a decrease in anxiety in $\mathrm{C} 57 \mathrm{BL} / 6$ mice and confirm that $\mathrm{BALB} / \mathrm{c}$ are more anxious than $\mathrm{C} 57 \mathrm{BL} / 6$ mice.

\section{Light/dark box}

Maternal separation did not have any effect on anxiety-related behavior in the L/DB (Figure 5). Indeed, for the latency to dark part (Figure 5A), two-way ANOVA indicated there was no overall MS effect $[F(2,73)=0.59 ; p=0.558]$ and no MS $\times$ strain interaction $[F(2,73)=0.69 ; p=0.504]$; however, there was a strain effect $[F(1,73)=23.60 ; p<0.0001]$. Post hoc analysis revealed that control and protocol $1 \mathrm{C} 57 \mathrm{BL} / 6$ mice displayed a lower latency to enter the dark part than their respective BALB/c mice (control, $p=0.003$; protocol 1, $p<0.0001$; protocol $2, p=0.071$ ), but there was no difference between control and MS mice in both strains (C57BL/6 control vs. protocol 1, $p=0.798$; control vs. protocol 2, $p=0.501$; $\mathrm{BALB} / \mathrm{c}$ control vs. protocol $1, p=0.324$; control vs. protocol 2, $p=0.715)$.

Regarding the number of transitions between the light and dark part (Figure 5B), two-way ANOVA showed there was no overall MS effect $[F(2,71)=0.5 ; p=0.606]$ and no MS $\times$ strain interaction $[F(2,71)=2.75 ; p=0.071]$; however, there was a strain effect $[F(1,71)=78.08 ; p<0.0001]$. Post hoc analysis further revealed that separated protocol 1, but not protocol 2, C57BL/6 mice displayed a higher number of transitions than control animals (protocol 1, $p=0.021$; protocol $2, p=0.765)$, whereas there was no difference in BALB/c (control vs. protocol 1, $p=0.37$; control vs. protocol 2, $p=0.639$ ). Also, post hoc test showed C57BL/6 mice of all groups presented with a higher number of transitions than all BALB/c mice (all groups $p<0.0001$ ).

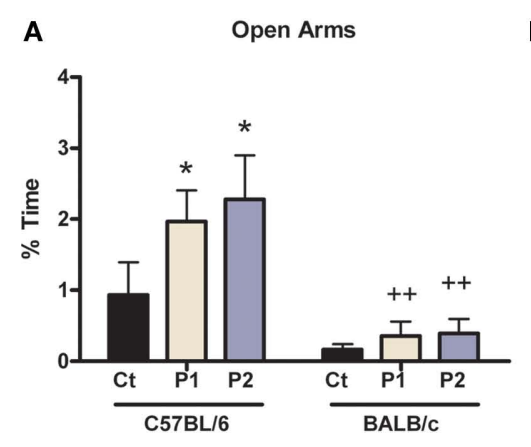

B

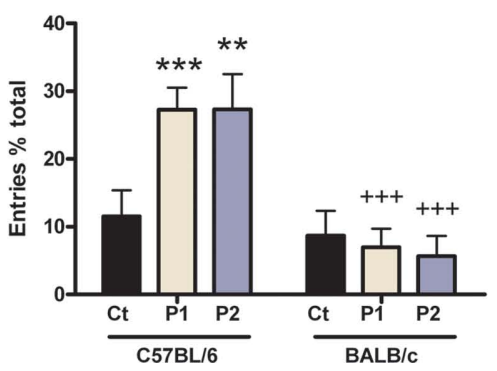

C

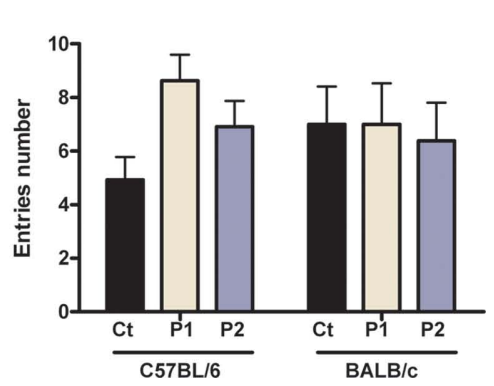

FIGURE 4 | Effect of MS on anxiety behavior in the elevated plus-maze. MS C57BL/6 mice of both protocols spent more time in the open arms (A) and presented with higher \% entries in open arms (B) than control animals, but there was no change in the total number of entries (C). There were also strain differences as MS C57BL/6 mice displayed higher \% time and \% entries in open arms exploration than their respective MS BALB/c mice. $n=11-19$ per strain per stress condition. Data expressed as means \pm SEM. Black " $\mathrm{Ct}$," control AFR groups; white "P1," protocol 1; blue "P2," protocol 2. " $p<0.05$, * $p<0.01$, ${ }^{* * *} p<0.001$ stress vs. control groups; ${ }^{+} p<0.05,{ }^{+} p<0.01,{ }^{++} p<0.001$ ， C57BL/6 vs. BALB/c mice. 
The time spent in the light part was also assessed (Figure 5C) and two-way ANOVA indicated there was no overall MS effect $[F(2,71)=0.17 ; p=0.848]$, no $\mathrm{MS} \times$ strain interaction $[F(2,71)=0.25 ; p=0.78]$, and no strain effect $[F(1,71)=0.09$; $p=0.77]$. Overall, these data suggest that MS protocol 1 induced a decrease in anxiety in $\mathrm{C} 57 \mathrm{BL} / 6$ and confirm that $\mathrm{BALB} / \mathrm{c}$ mice are more anxious than $\mathrm{C} 57 \mathrm{BL} / 6$ mice under baseline conditions.

\section{Forced swim test}

Maternal separation did not have any effect on antidepressantlike behavior in the FST (Figure 6). Indeed, for the latency to immobility (Figure 6A), two-way ANOVA revealed there was no MS effect $[F(2,75)=0.01, p=0.991]$ and no MS $\times$ strain interaction $[F(2,75)=1.92 ; p=0.154]$; however, there was a strain effect $[F(1,75)=69.13 ; p<0.0001]$. Post hoc analysis further indicated that all groups of $\mathrm{C} 57 \mathrm{BL} / 6$ mice displayed a significantly higher latency than their respective BALB/c groups $(p<0.0001)$, but there was no difference between control and MS groups (C57BL/6 control vs. protocol 1, $p=0.148$; control vs. protocol 2, $p=0.894)$; $\mathrm{BALB} / \mathrm{c}$ control vs. protocol $1, p=0.283$; control vs. protocol 2, $p=0.953)$.
For the time of immobility (Figure 6B), two-way ANOVA did not show any $\mathrm{MS}$ effect $[F(2,74)=0.57 ; p=0.57]$, $\mathrm{MS} \times$ strain interaction $[F(2,74)=0.52 ; p=0.596]$ or strain effect $[F(1,74)=1.91$; $p=0.172]$. This indicates that BALB/c mice tend to display higher depression-like behavior than C57BL/6 animals.

\section{MATERNAL SEPARATION-INDUCED EFFECTS ON PHYSIOLOGY: THYMUS, SPLEEN WEIGHT, COLON LENGTH, AND FECAL OUTPUT IN THE OPEN-FIELD}

For technical reasons, spleen and thymus weights of some animals could not be measured. For spleens weight (Table 2), two-way ANOVA showed there was no overall MS effect $[F(2,33)=0.69$; $p=0.507]$; however, there was a MS $\times$ strain interaction $[F(2,33)=5.32 ; p=0.0099]$ and a strain effect $[F(1,33)=45.39$; $p<0.0001]$. Post hoc analysis further revealed that all C57BL/6 mice displayed significantly lighter spleen than all BALB/c animals (controls, $p=0.05$, both MS protocols, $p<0.0001$ ), but there was no difference between control and MS groups (C57BL/6 control vs. protocol 1, $p=0.255$; control vs. protocol $2, p=0.315$; $\mathrm{BALB} / \mathrm{c}$ control vs. protocol $1, p=0.122$; control vs. protocol 2, $p=0.104)$.

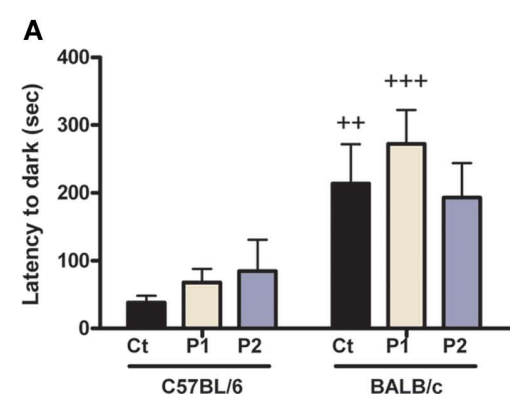

FIGURE 5 | Effect of MS on anxiety behavior in the light/dark box. MS had no overall effect in either of the two strains in latency do dark (A) and time in the light part (C). However, MS protocol 1 C57BL/6 mice displayed increased number of transitions (B) than control animals. There were also strains differences with control and protocol 1 C57BL/6 mice displaying lower latency to
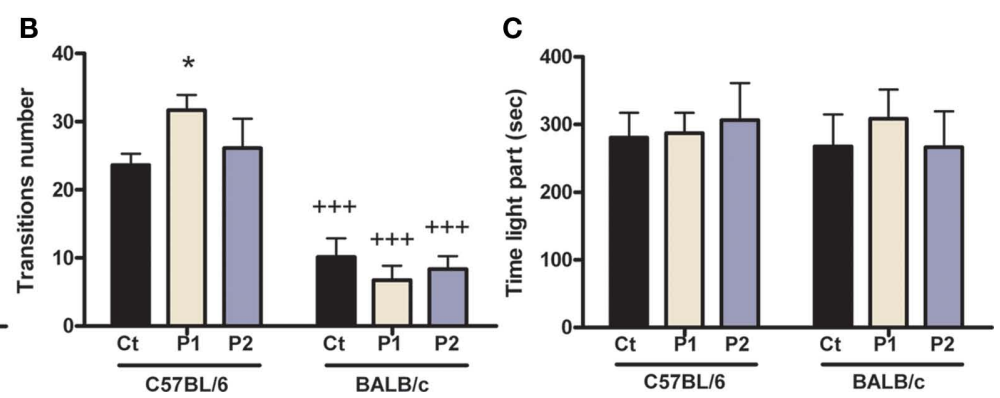

dark than respective BALB/c mice and all C57BL/6 mice displaying higher number of transitions than their respective BALB/c mice. $n=11-19$ per strain per stress condition. Data expressed as means \pm SEM. Black "Ct," control AFR groups; white "P1," protocol 1; blue "P2," protocol 2 . * $p<0.05$, stress vs. control groups; ${ }^{+} p<0.01,{ }^{++} p<0.001, \mathrm{C} 57 \mathrm{BL} / 6$ vs. BALB/c mice.

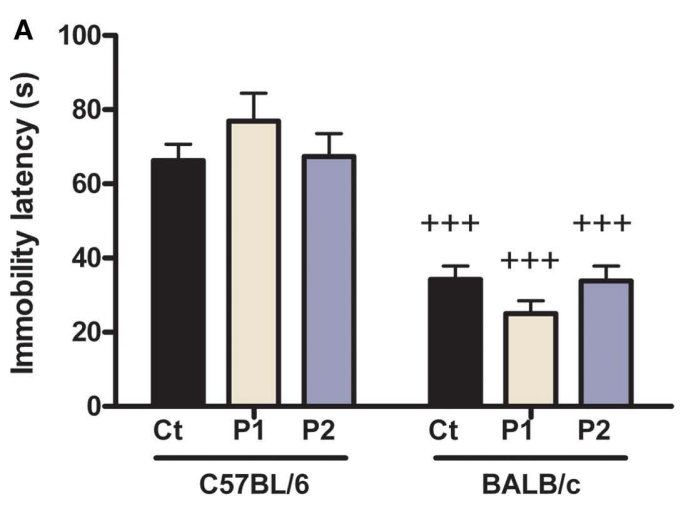

FIGURE 6 | Effect of MS on depression-related behavior in the forced swim test. MS had no overall effect in either strain in latency to immobility (A) or time of immobility (B). However, C57BL/6 mice of all groups displayed longer latency

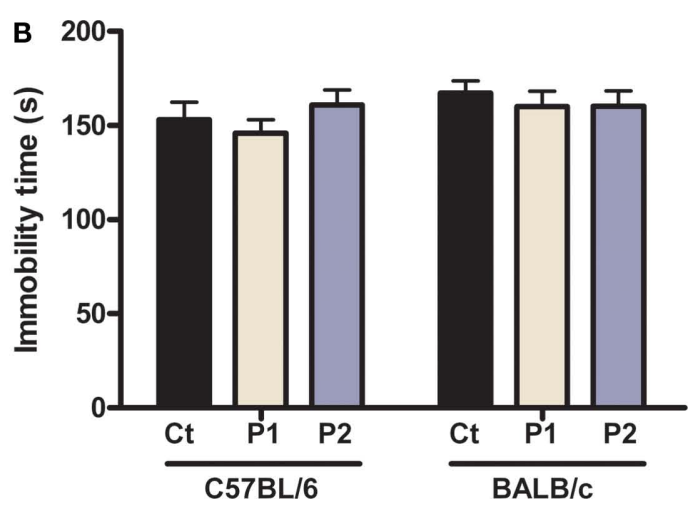

to immobility than BALB/c mice. $n=11-19$ per strain per stress condition. Data expressed as means \pm SEM. Black "Ct," control AFR groups; white "P1," protocol 1; blue "P2," protocol 2. ${ }^{+"} p<0.001, \mathrm{C} 57 \mathrm{BL} / 6$ vs. BALB/c mice. 
Table 2 | Effect of MS on physiological parameters.

\begin{tabular}{|c|c|c|c|c|c|c|}
\hline \multirow{2}{*}{$\begin{array}{l}\text { Tissue weight as } \\
\% \text { body weight }\end{array}$} & \multicolumn{3}{|c|}{ C57BL/6 } & \multicolumn{3}{|c|}{$\mathrm{BALB} / \mathrm{c}$} \\
\hline & Control & Protocol 1 & Protocol 2 & Control & Protocol 1 & Protocol 2 \\
\hline Spleen & $0.0811 \pm 0.0047$ & $0.0751 \pm 0.0032$ & $0.075 \pm 0.0047$ & $0.094 \pm 0.0042^{+}$ & $0.1055 \pm 0.0061^{+++}$ & $0.1046 \pm 0.0034^{+++}$ \\
\hline Thymus & $0.00557 \pm 0.0023$ & $0.0593 \pm 0.0017$ & $0.0608 \pm 0.0029$ & $0.0365 \pm 0.0026^{+++}$ & $0.0424 \pm 0.0051^{+++}$ & $0.0434 \pm 0.0028^{+++}$ \\
\hline Colon length (cm) & $7.4 \pm 0.2$ & $7.6 \pm 0.1$ & $7.4 \pm 0.2$ & $12 \pm 0.3^{+++}$ & $11.2 \pm 0.3^{*,+++}$ & $11.9 \pm 0.4^{+\ldots}$ \\
\hline
\end{tabular}

MS had no effect on spleen and thymus weight in either strains. Protocol 1 induced a reduction in colon length in BALB/C mice compared with control group. Both MS protocols induced reduced defecation in the open-field in BALB/C mice compared with controls. There were strains differences with MS C57BL/6 mice of both protocols displaying lighter spleen, heavier thymus, shorter colon, and higher number of fecal pellets in the open-field than their respective BALB/C mice. $n=4-11$ for spleen; 5-12 for thymus; $n=11-19$ for colon and fecal pellets. Data expressed as means \pm SEM. Black "Ct," control AFR groups; white "P1," protocol 1; blue "P2," protocol 2. ${ }^{*} p<0.05,{ }^{* * *} p<0.001$ stress vs. control groups, ${ }^{+} p<0.05,{ }^{++} p<0.001$, C57BL/6 vs. BALB/C mice.

For thymus weight (Table 2), two-way ANOVA showed MS had no overall effect $[F(2,47)=1.03 ; p=0.364]$ and there was no $\mathrm{MS} \times$ strain interaction $[F(2,47)=0.26 ; p=0.772]$. However, there was an overall strain effect $[F(1,65)=61.75 ; p<0.0001]$. Post hoc test indicated that C57BL/6 mice of all groups displayed lighter thymus than all BALB/c mice $(p<0.0001)$, but there was no difference between control and MS groups (BALB/c control vs. protocol 1, $p=0.172$; control vs. protocol 2, $p=0.073$; C57BL/6 control vs. protocol 1, $p=0.305$; control vs. protocol 2, $p=0.203$ ).

For the colon length (Table 2), two-way ANOVA did not highlight any MS effect $[F(2,75)=0.88 ; p=0.417]$ or $\mathrm{MS} \times$ strain interaction $[F(2,75)=2.43 ; p=0.095]$, but showed an overall strain effect $[F(1,75)=418.42 ; p<0.0001]$. Post hoc analysis indicated that $\mathrm{C} 57 \mathrm{BL} / 6$ mice of all groups displayed shorter colon than all BALB/c mice $(p<0.0001)$, but also that protocol $1 \mathrm{MS}$ BALB/c displayed shorter colon than control mice $(p=0.034)$; however, there was no other difference between control and MS groups (C57BL/6 control vs. protocol 1, $p=0.548$; control vs. protocol $2, p=0.976 ; \mathrm{BALB} / \mathrm{c}$ control vs. protocol 2, $p=0.747)$.

Regarding the number of fecal outputs produced in the OF (Table 2), two-way ANOVA revealed there was an overall MS effect $[F(2,71)=5.65 ; p=0.0053]$, a MS $\times$ strain interaction $[F(2,71)=7.53 ; p=0.0011]$, and a strain effect $[F(1,71)=97.16$; $p<0.0001]$. Post hoc test showed MS BALB/c mice produced a lower number of fecal pellets than control animals (protocol $1, p=0.014$; protocol 2, $p<0.0001$ ), but there was no difference in $\mathrm{C} 57 \mathrm{BL} / 6$ (protocol 1, $p=0.068$; protocol $2, p=0.486$ ). These results suggest a decreased colonic motility in BALB/c MS animals. Also, all C57BL/6 mice produced significantly less fecal outputs than $\mathrm{BALB} / \mathrm{c}$ mice (control, $p<0.0001$; protocol 1, $p<0.0001$; protocol 2, $p=0.024$ ).

\section{DISCUSSION}

The aim of this study was to develop a MS model in the mouse which could be used to investigate brain-gut axis disorders which have been strongly linked to early-life stress (Anisman et al., 1998; Holmes et al., 2005; Barreau et al., 2007; O’Mahony et al., 2009; Schmidt et al., 2011). Although rat models already exist, mice present the advantage of being more easily genetically manipulated, more cost-effective and easier to house than rats (Cryan and Holmes, 2005; Jacobson and Cryan, 2007). However, in general, our data employing two different MS protocols in two different strains, failed to show any robust change that would indicate that MS would be a suitable inducing agent to model brain-gut axis dysfunction or psychiatric disorders in mice. Indeed, this was despite us following recommendations from previous studies to increase stress severity, such as separating pups from each other or using no bedding during the MS period (D'Amato et al., 1992; Anisman et al., 1998; Millstein and Holmes, 2007).

This absence of general effect of MS on mice is in marked contrast with what is observed in our laboratory using a similar rat model of 3-h daily separation as well. Early-life stress in SpragueDawley male rats increases anxiety levels (OF task), visceral sensitivity (colorectal distension test) and colonic motility (fecal output in OF arena) (O'Mahony et al., 2009) in adulthood. Other studies have also reported that mice appear to be resistant to chronic MS procedure, with no change in anxiety parameters in C57BL/6J and CD1 mice (Macri and Laviola, 2004; Parfitt et al., 2004; Millstein and Holmes, 2007). On the other hand, some studies show chronic MS in mice can lead to behavioral changes. Indeed, increased anxiety following MS has been reported in the EPM and novel object exploration (Venerosi et al., 2003; Veenema et al., 2007) as well as evidences of increased depression-related behavior in the FST (MacQueen et al., 2003). However, cautious interpretation of the latter should always be observed as discrepancies exist in the literature regarding the real nature of the behavior displayed by mice (Pryce and Seifritz, 2011), with this test being more believed to constitute a test to screen antidepressant treatments (Cryan and Mombereau, 2004; Cryan et al., 2005). Nonetheless, difficulties are still experienced in establishing a robust model with consistent stress-induced behavioral changes. Such discrepancies are well known and it is acknowledged in the literature that it is difficult to establish an early-life stress mouse model (Millstein and Holmes, 2007; O'Mahony et al., 2011). Noteworthy, it has been suggested in a recent study that stress-induced differences may not be highlighted when mice behavior is scored for the total time of a given task but rather when data are analyzed in a time-dependent manner (van Heerden et al., 2010). Therefore, we also analyzed the data of OF in a time-wise manner, but no MS effect raised either. The other behavioral tasks were not analyzed in a time-dependent manner as some changes already occurred, for instance in the EPM, when analyzing the data for the total duration of the test. 
The reasons underlying the absence of robust sensitivity to MS in mice, despite such findings occurring in other species such as rats (O'Mahony et al., 2011) and primates (Pryce et al., 2005) is a matter of debate. One of the main reasons suggested by (Millstein and Holmes, 2007) is the compensation in maternal care that is provided by the mothers at reunion with pups. Indeed, the reunion of mothers with their pups elicits over-care behavior that may compensate for the time of separation and counteract any negative effects of MS procedures. However, a recent study has shown that although extra maternal care behavior were given by BALB/c mothers to their pups, this was not sufficient to counterbalance early-life stress and pups still displayed increased anxiety at adulthood (Wei et al., 2010).

The length and time of onset of daily separation were also parameters to take into account, which is one of the reasons why we used a long (P1-14) or a short (P6-10) separation protocols. We tested both the long protocol as it is one of the most commonly used in literature (Romeo et al., 2003; Veenema et al., 2007) as well as the short one (Groer et al., 2002) because we thought that separating mothers and pups for only a few days would disorganize the dyadic interaction and increase stress severity. However, neither protocol induced increased anxiety or depression-related behavioral changes in adulthood. Different protocols have been investigated in mice, from 1 to 18 days of separation (MacQueen et al., 2003; Macri and Laviola, 2004; Parfitt et al., 2004) and it has been suggested that $6 \mathrm{~h}$ of separation would be more likely to induce changes rather than 3 h of separation (Kulikov et al., 1995; Parfitt et al., 2004).

The exact postnatal days the pups are separated for also has an influence on the impact of MS. Three hours of daily separation starting at $\mathrm{P} 4$ does not seem to be robust enough in gerbils (Jaworska et al., 2008) but induced changes following 18 days separation in the FST in mice (MacQueen et al., 2003). Also, some MS protocols starting at $\mathrm{P} 0$ did not bring robust changes in behavior at adulthood (Parfitt et al., 2004; Millstein and Holmes, 2007). Moreover, the hyporesponsiveness of the HPA axis during the early postnatal period (Slattery and Neumann, 2008) suggests that initiation of early-life separation before P3 may not be suitable to induce persistent effects (Groer et al., 2002). Therefore, although we used this protocol in the present study and MS had no major effect on adult behavior, $\mathrm{P} 1$ or 2 to $\mathrm{P} 14$ separation is the most commonly used protocol and which also seems to induce behavioral and physiological alterations (Romeo et al., 2003; Veenema et al., 2007).

The effects of other modifications of the MS protocol could also be investigated. It has recently been suggested that to create a robust early-life stress model, the MS protocol could be combined with another stressor, or the MS procedure could be made unpredictable by alternating the time of day when the separation takes place (Franklin et al., 2010; George et al., 2010; Niwa et al., 2010), because conducting MS at the same time each day may result in mice habituating to the stressor. Future studies should investigate if these parameters differentially affect adult behavioral and physiology in BALB/c compared to C57BL/6 mice.

Although overall MS did not induce increased anxiety or depression-related behavior, MS C57BL/6 animals of both protocols paradoxically displayed evidence of increased exploration in the EPM and MS C57BL/6 protocol 2 (short protocol), decreased anxietyrelated parameters in the $\mathrm{L} / \mathrm{DB}$, without evidence of hyperactivity or modified locomotor activity in the OF. Although in the present study, mice of both MS protocols were separated daily for $3 \mathrm{~h}$, the decreased anxiety displayed by mice is similar to that induced by 15-min chronic daily separation ("handling"), that is described to induce either decreased anxiety or no behavioral impairment (D’Amato et al., 1998; Millstein and Holmes, 2007). Interestingly, any MS-induced changes occurring in behavior were restricted to C57BL/6 mice, and these changes involved a reduction, rather than an increase, in anxiety-related behavior. These results were surprising as the two mouse strains selected for these two MS procedures were carefully chosen for their reported differences in anxiety-related behaviors, BALB/c mice displaying higher anxiety than $\mathrm{C} 57 \mathrm{BL} / 6$ animals and being proposed as a model of pathological anxiety (Belzung and Griebel, 2001; Jacobson and Cryan, 2007; Millstein and Holmes, 2007; O’Mahony et al., 2010). Therefore, as expected, innate strain differences between control animals occurred in behavioral assessments, with BALB/c mice displaying higher baseline anxiety levels. However, we assumed the innately anxious BALB/c would be more sensitive to MS separation than C57BL/6 mice. One of the reasons for these findings may be the difference in maternal care pups received from their mother at reunion. C57BL/6J mice are generally less anxious than BALB/cJ which may thus contribute to the fact that mothers from these strains being referred to as "good and bad mothers" respectively (Anisman et al., 1998; Millstein and Holmes, 2007). These suggestions have also been confirmed by cross-fostering studies, where exchanging C57BL/6 and BALB/c mothers and pups lead to the opposite anxiety phenotype between the exchanged pups and their natural mother (Priebe et al., 2005). Therefore, C57BL/6 mice are described to be better mothers than BALB/c mice (Millstein and Holmes, 2007). As MS induces mothers to give extra maternal care at reunion with pups (Millstein and Holmes, 2007), C57BL/6 mothers may have better compensated for separation than $\mathrm{BALB} / \mathrm{c}$ mothers, giving better maternal care, resulting in a "handling" effect, decreasing offspring's stress at adulthood.

Also, a major difference between C57BL/6 and BALB/c mice that may be at the origin of their behavioral phenotype is the lower serotonin rates $\mathrm{BALB} / \mathrm{c}$ mice display compared with $\mathrm{C} 57 \mathrm{BL} / 6$ mice, that lies in the innate variation in the gene encoding central tryptophan hydroxylase (Zhang et al., 2004; Cervo et al., 2005; Jacobson and Cryan, 2007; Browne et al., 2011). Lower serotonin rates are known to be part of the pathophysiology of a broad range of psychiatric disorders ranging from hyperactivity to depression (Holmes et al., 2002; Young and Leyton, 2002; Popova, 2008). Therefore, lower brain levels of 5-HT in BALB/c mice may result in a differential reaction to early-life stress.

Fecal pellets released during the OF task were scored as an index of stress-induced autonomic response (Julio-Pieper et al., 2010; Wang et al., 2010). Interestingly, MS BALB/c (both long and short protocols) displayed decreased fecal outputs compared to control animals. Although somewhat surprising, we found similar results in BALB/c mice following social defeat stress (Savignac and Cryan, unpublished). The opposite effect was expected, as exposure to a novel environment increases fecal output (Barone et al., 2008; Wang et al., 2010). These data suggest mice may have displayed a decrease in colonic motility which would be relevant to IBS patients displaying a constipation phenotype, which has not been established in traditional IBS mouse models (Bercik et al., 2004; Kimball et al., 2005; Coates et al., 2006). 
Although MS mice did not display overall behavioral changes, some additional physiological parameters were analyzed. MS induced some modest evidence of body weight alterations in protocol 1 (long protocol), inducing a lower bodyweight in C57BL/6 mice compared with controls, only at an early stage (4 weeks old). However, these changes were not consistent and only at an isolated time-point therefore we cannot conclude that MS here had an overall effect on bodyweight. There is a lot of discrepancy in literature regarding stress and bodyweight changes. Indeed, both increases and decreases in bodyweight gain have been described, not only following early-life stress but also other types of stressors (Loizzo et al., 2006; Krishnan et al., 2007; Veenema et al., 2008; Savignac et al., 2011). Together, these data suggest that bodyweight alterations induced by stress are under complex regulatory processes and may depend on the nature and context of stress.

Maternal separation did not induce any change, overall, in spleen and thymus weight and only protocol 1 (long protocol) induced reduced colon length in BALB/c mice. Splenomegaly has been associated with increased recruitment of immune cells to fight infection or combat the effects of stress whereas thymus weight alterations results in changes in the number of immature thymocytes, which are sensitive to stress-induced activation (Reber et al., 2007). Colon length has also been described to be reduced in the case of colonic inflammation (Reber et al., 2007). It would be tempting to suggest that protocol 1 (long protocol) induced some sort of mild inflammation in BALB/c mice; however, no other physiological change occurred. Taken together, the absence of robust physiological changes in the mice across the protocols gives further indication that these mice were resistant to the two early-life stress protocols used. Accordingly, as all these parameters are described to be altered in the case of increased stress (Bartolomucci et al., 2005; Reber et al., 2007), further physiological assessments were not conducted in the present study.

Finally, although the two mouse strains used in this study did not display behavioral and physiological alteration, the data obtained still bring important information for future studies. First, a protocol that is well established in rats, does not consistently work in mice, further emphasizing the fundamental differences that occur between studies conducted with different animal species. Therefore, caution should always be taken in the interpretation of data and the generalization to human disorders. Also, even though the long protocol we used here has been shown to work in other laboratories using C57BL/6 mice (Veenema et al., 2007), it did

\section{REFERENCES}

Anisman, H., Merali, Z., and Stead, J. D. (2008). Experiential and genetic contributions to depressive- and anxiety-like disorders: clinical and experimental studies. Neurosci. Biobehav. Rev. 32, 1185-1206.

Anisman, H., Zaharia, M. D., Meaney, M. J., and Merali, Z. (1998). Do early-life events permanently alter behavioral and hormonal responses to stressors? Int. J. Dev. Neurosci. 16, 149-164.

Bair, M. J., Robinson, R. L., Katon, W., and Kroenke, K. (2003). Depression and pain comorbidity: a literature review. Arch. Intern. Med. 163, 2433-2445.

Barone, F. C., Barton, M. E., White, R. F., Legos, J. J., Kikkawa, H., Shimamura, M., Kuratani, K., and Kinoshita, M. (2008). Inhibition of phosphodiesterase type 4 decreases stressinduced defecation in rats and mice. Pharmacology 81, 11-17.

Barreau, F., Ferrier, L., Fioramonti, J., and Bueno, L. (2007). New insights in the etiology and pathophysiology of irritable bowel syndrome: contribution of neonatal stress models. Pediatr. Res. $62,240-245$

not work in our laboratory, which stresses out the importance of inter-laboratory testing and the potential for substrain differences in mice. As a result, the effects of a particular type of stress must be highly dependent on intra-laboratory conditions and rely on subtle environmental variations. Nonetheless, our data presented here should clearly influence future attempts to establish a mouse MS model. Our data further highlight the importance of understanding the underlying mechanisms of stress-resistance that appears to be particularly sensitive to slight protocol variations. Other studies have described that following a 10-day social defeat stress, about $40 \%$ of mice develop resilience to stress, due to molecular adaptations in brain reward pathways (Krishnan et al., 2007). Hence, our data also demonstrate the impact that environmental conditions can have over genetic predisposition. Given the genetic background differences between the two mouse strains we used in this study, $\mathrm{BALB} / \mathrm{c}$ were predicted to be more stress-sensitive than $\mathrm{C} 57 \mathrm{BL} / 6$ mice. Therefore, it would be interesting to investigate what molecular mechanisms these two different mouse strains have in common in adapting to environmental changes.

In conclusion establishing an early-life stress mouse model relies on numerous parameters, small modifications inducing large inter- and intra-mouse strain differences. Thus, although precautions were taken to ensure the severity of the stressors, overall mice remained resistant to both a long and short maternal separation protocols. These results thus build on previous data showing that resistance to MS-induced anxiety is often observed in mice (Millstein and Holmes, 2007). Thus, increasing the length of daily separation combined with an additional and/or unpredictable stressor may be required to induce robust and consistent phenotypical impairments relevant to brain-gut axis disorders.

\section{ACKNOWLEDGMENTS}

The authors would like to thank Drs. Olivia O'Leary and Siobhain O'Mahony for helpful comments on the paper. The advice and/or technical assistance of Colette Manley, Patrick Fitzgerald, Cliona O'Mahony, Caroline Browne, and Dr. Niall Hyland is greatly appreciated. The Alimentary Pharmabiotic Centre is a research center funded by Science Foundation Ireland (SFI), through the Irish Government's National Development Plan. The authors and their work were supported by SFI (grant numbers: 02/CE/B124 and 07/ $\mathrm{CE} / \mathrm{B} 1368)$. John F. Cryan is also funded by European Community's Seventh Framework Programme; grant number: FP7/2007-2013, Grant Agreement 201714.

Bartolomucci, A., Palanza, P., Sacerdote, P., Panerai, A. E., Sgoifo, A., Dantzer, R., and Parmigiani, S. (2005). Social factors and individual vulnerability to chronic stress exposure. Neurosci. Biobehav. Rev. 29, 67-81.

Belzung, C., and Griebel, G. (2001). Measuring normal and pathological anxiety-like behaviour in mice: a review. Behav. Brain Res. 125, 141-149.

Bercik, P., Wang, L., Verdu, E. F., Mao, Y. K., Blennerhassett, P., Khan, W. I., Kean, I., Tougas, G., and Collins, S. M. (2004). Visceral hyperalgesia and intestinal dysmotility in a mouse model of postinfective gut dysfunction. Gastroenterology 127, 179-187.

Browne, C.A., Clarke, G., Dinan, T.G., and Cryan, J. F. (2011). Differential stressinduced alterations in tryptophan hydroxylase activity and serotonin turnover in two inbred mouse strains. Neuropharmacology 60, 683-691.

Cabib, S., Puglisi-Allegra, S., and D'Amato, F. R. (1993). Effects of postnatal stress on dopamine mesolimbic system responses to aversive experiences in adult life. Brain Res. 604, 232-239.

Calatayud, F., and Belzung, C. (2001). Emotional reactivity in mice, a case of 
nongenetic heredity? Physiol. Behav. $74,355-362$.

Caldji, C., Diorio, J., Anisman, H., and Meaney, M. J. (2004). Maternal behavior regulates benzodiazepine/ GABAA receptor subunit expression in brain regions associated with fear in BALB/c and C57BL/6 mice. Neuropsychopharmacology 29 , 1344-1352.

Carpenter, L. L., Carvalho, J. P., Tyrka, A. R., Wier, L. M., Mello, A. F., Mello, M. F., Anderson, G. M., Wilkinson, C. W., and Price, L. H. (2007). Decreased adrenocorticotropic hormone and cortisol responses to stress in healthy adults reporting significant childhood maltreatment. Biol. Psychiatry 62, 1080-1087.

Cervo, L., Canetta, A., Calcagno, E., Burbassi, S., Sacchetti, G., Caccia, S., Fracasso, C., Albani, D., Forloni, G., and Invernizzi, R. W. (2005). Genotype-dependent activity of tryptophan hydroxylase- 2 determines the response to citalopram in a mouse model of depression. J. Neurosci. 25, 8165-8172.

Charney, D. S., and Manji, H. K. (2004). Life stress, genes, and depression: multiple pathways lead to increased risk and new opportunities for intervention. Sci. STKE 2004, re5.

Coates, M. D., Johnson, A. C., GreenwoodVan Meerveld, B., and Mawe, G. M. (2006). Effects of serotonin transporter inhibition on gastrointestinal motility and colonic sensitivity in the mouse. Neurogastroenterol. Motil. 18, 464-471.

Crawley, J. N. (2008). Behavioral phenotyping strategies for mutant mice. Neuron 57, 809-818.

Cryan, J. F., Dalvi, A., Jin, S. H., Hirsch, B. R., Lucki, I., and Thomas, S. A. (2001). Use of dopamine-beta-hydroxylasedeficient mice to determine the role of norepinephrine in the mechanism of action of antidepressant drugs. J. Pharmacol. Exp. Ther. 298, 651-657.

Cryan, J. F., and Holmes, A. (2005). The ascent of mouse: advances in modelling human depression and anxiety. Nat. Rev. Drug Discov. 4, 775-790.

Cryan, J. F., Markou, A., and Lucki, I. (2002). Assessing antidepressant activity in rodents: recent developments and future needs. Trends Pharmacol. Sci. 23, 238-245.

Cryan, J. F., and Mombereau, C. (2004). In search of a depressed mouse: utility of models for studying depression-related behavior in genetically modified mice. Mol. Psychiatry 9, 326-357.

Cryan, J. F., Valentino, R. J., and Lucki, I. (2005). Assessing substrates underlying the behavioral effects of antidepressants using the modified rat forced swimming test. Neurosci. Biobehav Rev. 29, 547-569.

D'Amato, F. R., Cabib, S., Puglisi-Allegra, S., Patacchioli, F. R., Cigliana, G., Maccari, S., and Angelucci, L. (1992). Effects of acute and repeated exposure to stress on the hypothalamopituitary-adrenocortical activity in mice during postnatal development. Horm. Behav. 26, 474-485.

D'Amato, F. R., Cabib, S., Ventura, R., and Orsini, C. (1998). Long-term effects of postnatal manipulation on emotionality are prevented by maternal anxiolytic treatment in mice. Dev. Psychobiol. 32, 225-234.

Dinan, T. G. (2005). Stress: the shared common component in major mental illnesses. Eur. Psychiatry 20(Suppl. 3), $\mathrm{S} 326-\mathrm{S} 328$.

Dinan, T. G., Cryan, J., Shanahan, F., Keeling, P. W., and Quigley, E. M. (2010). IBS: an epigenetic perspective. Nat. Rev. Gastroenterol. Hepatol. 7, 465-471.

Drake, A. J., Tang, J. I., and Nyirenda, M. J. (2007). Mechanisms underlying the role of glucocorticoids in the early life programming of adult disease. Clin. Sci. 113, 219-232.

Engler, H., Engler, A., Bailey, M. T., and Sheridan, J. F. (2005). Tissue-specific alterations in the glucocorticoid sensitivity of immune cells following repeated social defeat in mice. $J$. Neuroimmunol. 163, 110-119.

Eriksson, E. M., Andren, K. I., Eriksson, H. T., and Kurlberg, G. K. (2008). Irritable bowel syndrome subtypes differ in body awareness, psychological symptoms and biochemical stress markers. World J. Gastroenterol. 14, 4889-4896.

Franklin, T. B., Russig, H., Weiss, I. C., Graff, J., Linder, N., Michalon, A., Vizi, S., and Mansuy, I. M. (2010). Epigenetic transmission of the impact of early stress across generations. Biol. Psychiatry 68, 408-415.

George, E. D., Bordner, K. A., Elwafi, H. M., and Simen, A. A. (2010). Maternal separation with early weaning: a novel mouse model of early life neglect. BMC Neurosci. 11, 123. doi: 10.1186/1471-2202-11-123

Groer, M. W., Hill, J., Wilkinson, J. E., and Stuart,A. (2002). Effects of separation and separation with supplemental stroking in BALb/c infant mice. Biol. Res. Nurs. 3, 119-131.

Holmes, A., le Guisquet, A. M., Vogel, E., Millstein, R. A., Leman, S., and Belzung, C. (2005). Early life genetic, epigenetic and environmental factors shaping emotionality in rodents. Neurosci. Biobehav. Rev. 29, 1335-1346.

Holmes, A., Murphy, D. L., and Crawley, J. N. (2002). Reduced aggression in mice lacking the serotonin transporter.
Psychopharmacology (Berl.) 161, 160-167.

Hotoleanu, C., Popp, R., Trifa, A. P., Nedelcu, L., and Dumitrascu, D. L. (2008). Genetic determination of irritable bowel syndrome. World $J$. Gastroenterol. 14, 6636-6640.

Jacobson, L. H., Bettler, B., Kaupmann, K., and Cryan, J.F. (2007a). Behavioral evaluation of mice deficient in $\operatorname{GABA}(\mathrm{B}(1))$ receptor isoforms in tests of unconditioned anxiety. Psychopharmacology (Berl.) 190 541-553.

Jacobson, L. H., Kelly, P. H., Bettler, B., Kaupmann, K., and Cryan, J. F. (2007b). Specific roles of GABA(B(1)) receptor isoforms in cognition. Behav. Brain Res. 181, 158-162.

Jacobson, L. H., and Cryan, J. F. (2007). Feeling strained? Influence of genetic background on depression-related behavior in mice: a review. Behav Genet. 37, 171-213.

Jaworska, N., Dwyer, S. M., and Rusak, B. (2008). Repeated neonatal separation results in different neurochemical and behavioral changes in adult male and female Mongolian gerbils. Pharmacol. Biochem. Behav. 88, 533-541.

Julio-Pieper, M., Hyland, N.P., Bravo, J.A. Dinan, T. G., and Cryan, J. F. (2010). A novel role for the metabotropic glutamate receptor-7: modulation of faecal water content and colonic electrolyte transport in the mouse. $B r$. J. Pharmacol. 160, 367-375.

Kimball, E. S., Palmer, J.M., D’Andrea, M. R., Hornby, P.J., and Wade, P. R. (2005). Acute colitis induction by oil of mustard results in later development of an IBS-like accelerated upper GI transit in mice. Am. J. Physiol. Gastrointest. Liver Physiol. 288, G1266-G1273.

Krishnan, V., Han, M. H., Graham, D. L., Berton, O., Renthal, W., Russo, S. J., Laplant, Q., Graham, A., Lutter, M., Lagace, D. C., Ghose, S., Reister, R. Tannous, P., Green, T. A., Neve, R. L. Chakravarty, S., Kumar, A., Eisch, A J., Self, D. W., Lee, F. S., Tamminga, C. A., Cooper, D. C., Gershenfeld, H. K. and Nestler, E. J. (2007). Molecular adaptations underlying susceptibility and resistance to social defeat in brain reward regions. Cell 131 , 391-404.

Krishnan,V., and Nestler,E. J. (2008). The molecular neurobiology of depression. Nature 455, 894-902.

Kulikov, A. V., Avgustinovich, D. F., Kolpakov, V. G., Maslova, G. B., and Popova, N. K. (1995). 5-HT2A serotonin receptors in the brain of rats and mice hereditarily predisposed to catalepsy. Pharmacol. Biochem. Behav. $50,383-387$.

Ladd, C. O., Huot, R. L., Thrivikraman, K. V., Nemeroff, C. B., and Plotsky,
P. M. (2004). Long-term adaptations in glucocorticoid receptor and mineralocorticoid receptor mRNA and negative feedback on the hypothalamo-pituitary-adrenal axis following neonatal maternal separation. Biol. Psychiatry 55, 367-375.

Lalonde, R. (2002). The neurobiological basis of spontaneous alternation. Neurosci. Biobehav. Rev. 26, 91-104.

Lazinski, M. J., Shea, A. K., and Steiner, M. (2008). Effects of maternal prenatal stress on offspring development: a commentary. Arch. Womens Ment. Health 11, 363-375.

Levine, S. (2005). Developmental determinants of sensitivity and resistance to stress. Psychoneuroendocrinology 30, 939-946.

Loizzo, A., Loizzo, S., Galietta, G., Caiola, S., Spampinato, S., Campana, G., Seghieri, G., Ghirlanda, G., and Franconi, F. (2006). Overweight and metabolic and hormonal parameter disruption are induced in adult male mice by manipulations during lactation period. Pediatr. Res. 59, 111-115.

MacQueen, G. M., Ramakrishnan, K., Ratnasingan, R., Chen, B., and Young, L. T. (2003). Desipramine treatment reduces the long-term behavioural and neurochemical sequelae of early-life maternal separation. Int. J. Neuropsychopharmacol. 6, 391-396.

Macri, S., and Laviola, G. (2004). Single episode of maternal deprivation and adult depressive profile in mice: interaction with cannabinoid exposure during adolescence. Behav. Brain Res. $154,231-238$

Macri, S., and Wurbel, H. (2006). Developmental plasticity of HPA and fear responses in rats: a critical review of the maternal mediation hypothesis. Horm. Behav. 50, 667-680.

Mayer, E. A., Bradesi, S., Chang, L., Spiegel, B. M., Bueller, J. A., and Naliboff, B. D. (2008). Functional GI disorders: from animal models to drug development. Gut 57, 384-404.

McKernan, D.P., Dinan, T. G., and Cryan, J. F. (2009). "Killing the Blues": a role for cellular suicide (apoptosis) in depression and the antidepressant response? Prog. Neurobiol. 88, 246-263.

Mertz, H. R. (2003). Overview of functional gastrointestinal disorders: dysfunction of the brain-gut axis. Gastroenterol. Clin. North Am. 32, 463-476, v.

Millstein, R. A., and Holmes, A. (2007). Effects of repeated maternal separation on anxiety- and depressionrelated phenotypes in different mouse strains. Neurosci. Biobehav. Rev. 31, 3-17.

Moles, A., Rizzi, R., and D'Amato, F. R. (2004). Postnatal stress in mice: does "stressing" the mother have the same 
effect as "stressing" the pups? Dev. Psychobiol. 44, 230-237.

Niwa, M., Matsumoto, Y., Mouri, A., Ozaki, N., and Nabeshima, T. (2010). Vulnerability in early life to changes in the rearing environment plays a crucial role in the aetiopathology of psychiatric disorders. Int. J. Neuropsychopharmacol. 1-19. 10.1017/S1461145710001239. [Epub ahead of print].

North, C. S., Hong, B. A., and Alpers, D. H. (2007). Relationship of functional gastrointestinal disorders and psychiatric disorders: implications for treatment. World J. Gastroenterol. 13, 2020-2027.

O’Mahony, C. M., Sweeney, F. F., Daly, E., Dinan, T. G., and Cryan, J. F. (2010). Restraint stress-induced brain activation patterns in two strains of mice differing in their anxiety behaviour. Behav. Brain Res. 213, 148-154.

O’Mahony, S. M., Hyland, N. P., Dinan, T. G., and Cryan, J. F. (2011). Maternal separation as a model of brain-gut axis dysfunction. Psychopharmacology (Berl.) 214, 71-88.

O’Mahony, S. M., Marchesi, J. R., Scully, P., Codling, C., Ceolho, A. M., Quigley, E. M., Cryan, J. F., and Dinan, T. G. (2009). Early life stress alters behavior, immunity, and microbiota in rats: implications for irritable bowel syndrome and psychiatric illnesses. Biol. Psychiatry 65, 263-267.

O'Malley, D., Dinan, T. G., and Cryan, J. F. (2010). Alterations in colonic corticotropin-releasing factor receptors in the maternally separated rat model of irritable bowel syndrome: differential effects of acute psychological and physical stressors. Peptides 31 , 662-670.

Oreland, S., Pickering, C., Gokturk, C., Oreland, L., Arborelius, L., and Nylander, I. (2009). Two repeated maternal separation procedures differentially affect brain 5-hydroxytryptamine transporter and receptors in young and adult male and female rats. Brain Res. 1305(Suppl.), S37-S49.

Parfitt, D. B., Levin, J. K., Saltstein, K. P., Klayman, A. S., Greer, L. M., and Helmreich, D. L. (2004). Differential early rearing environments can accentuate or attenuate the responses to stress in male C57BL/6 mice. Brain Res. 1016, 111-118.

Popova, N. K. (2008). From gene to aggressive behavior: the role of brain serotonin. Neurosci. Behav. Physiol.38, 471-475.

Priebe, K., Romeo, R. D., Francis, D. D., Sisti, H. M., Mueller, A., McEwen, B. S., and Brake, W. G. (2005). Maternal influences on adult stress and anxietylike behavior in C57BL/6J and BALB/ cJ mice: a cross-fostering study. Dev. Psychobiol. 47, 398-407.

Pryce, C.R., Ruedi-Bettschen, D., Dettling, A. C., Weston, A., Russig, H., Ferger, B., and Feldon, J. (2005). Long-term effects of early-life environmental manipulations in rodents and primates: potential animal models in depression research. Neurosci. Biobehav. Rev. 29, 649-674.

Pryce, C. R., and Seifritz, E. (2011). A translational research framework for enhanced validity of mouse models of psychopathological states in depression. Psychoneuroendocrinology, 36, 308-329.

Reber, S. O., Birkeneder, L., Veenema, A. H., Obermeier, F., Falk, W., Straub, R. H., and Neumann, I. D. (2007). Adrenal insufficiency and colonic inflammation after a novel chronic psycho-social stress paradigm in mice: implications and mechanisms. Endocrinology 148, 670-682.

Reber, S. O., Obermeier, F., Straub, R. H., Falk, W., and Neumann, I. D. (2006). Chronic intermittent psychosocial stress (social defeat/overcrowding) in mice increases the severity of an acute DSS-induced colitis and impairs regeneration. Endocrinology 147, 4968-4976.

Romeo, R. D., Mueller, A., Sisti, H. M., Ogawa, S., McEwen, B. S., and Brake, W. G. (2003). Anxiety and fear behaviors in adult male and female C57BL/6 mice are modulated by maternal separation. Horm. Behav. 43, 561-567.

Savignac, H. M., Hyland, N. P., Dinan, T. G., and Cryan, J. F. (2011). The effects of repeated social interaction stress on behavioural and physiological param- eters in a stress-sensitive mouse strain. Behav. Brain Res. 216, 576-584.

Schmidt, M.V., Wang, X. D., and Meijer, O. C. (2011). Early life stress paradigms in rodents: potential animal models of depression? Psychopharmacology (Berl.) 214, 131-140.

Slattery, D.A., and Neumann, I. D. (2008). No stress please! Mechanisms of stress hyporesponsiveness of the maternal brain. J. Physiol. 586, 377-385.

Uhelski, M. L., and Fuchs, P. N. (2010) Maternal separation stress leads to enhanced emotional responses to noxious stimuli in adult rats. Behav. Brain Res. 212, 208-212.

van Heerden, J. H., Russell, V., Korff, A., Stein, D. J., and Illing, N. (2010) Evaluating the behavioural consequences of early maternal separation in adult C57BL/6 mice; the importance of time. Behav. Brain Res. 207, 332-342.

Veenema, A. H., Blume, A., Niederle, D., Buwalda, B., and Neumann, I. D (2006). Effects of early life stress on adult male aggression and hypothalamic vasopressin and serotonin. Eur. J. Neurosci. 24, 1711-1720.

Veenema, A. H., Bredewold, R., and Neumann, I. D. (2007). Opposite effects of maternal separation on intermale and maternal aggression in C57BL/6 mice: link to hypothalamic vasopressin and oxytocin immunoreactivity. Psychoneuroendocrinology 32, 437-450.

Veenema, A. H., Reber, S. O., Selch, S. Obermeier, F., and Neumann, I. D. (2008). Early life stress enhances the vulnerability to chronic psychosocial stress and experimental colitis in adult mice. Endocrinology 149, 2727-2736.

Venerosi, A., Cirulli, F., Capone, F., and Alleva, E. (2003). Prolonged perinatal AZT administration and early maternal separation: effects on social and emotional behaviour of periadolescent mice. Pharmacol.Biochem. Behav.74,671-681.

Wachs, T. D. (2009). Models linking nutritional deficiencies to maternal and child mental health. Am. J. Clin. Nutr. 89, 935S-939S.

Wang, L., Gourcerol, G., Yuan, P. Q., Wu, S. V., Million, M., Larauche, M., and
Tache, Y. (2010). Peripheral peptide $\mathrm{YY}$ inhibits propulsive colonic motor function through $\mathrm{Y} 2$ receptor in conscious mice. Am. J. Physiol. Gastrointest. Liver Physiol. 298, G45-G56.

Weaver, S. A., Diorio, J., and Meaney, M. J. (2007). Maternal separation leads to persistent reductions in pain sensitivity in female rats. J. Pain 8, 962-969.

Wei, L., David, A., Duman, R. S., Anisman, H., and Kaffman, A. (2010). Early life stress increases anxiety-like behavior in Balbc mice despite a compensatory increase in levels of postnatal maternal care. Horm. Behav. 57, 396-404.

Wood, J.D. (2007). Neuropathophysiology of functional gastrointestinal disorders. World J. Gastroenterol. 13, 1313-1332.

Wurtman, R. J. (2005). Genes, stress, and depression. Metab. Clin. Exp. 54, 16-19.

Young, S. N., and Leyton, M. (2002). The role of serotonin in human mood and social interaction. Insight from altered tryptophan levels. Pharmacol. Biochem. Behav. 71, 857-865.

Zhang, X., Beaulieu, J. M., Sotnikova, T. D., Gainetdinov, R. R., and Caron, M. G. (2004). Tryptophan hydroxylase-2 controls brain serotonin synthesis. Science 305, 217.

Conflict of Interest Statement: The authors declare that the research was conducted in the absence of any commercial or financial relationships that could be construed as a potential conflict of interest.

Received: 21 December 2010; accepted: 03 March 2011; published online: 04 April 2011.

Citation: Savignac HM, Dinan TG and Cryan JF (2011) Resistance to early-life stress in mice: effects of genetic background and stress duration. Front. Behav. Neurosci. 5:13. doi: 10.3389/fnbeh.2011.00013 Copyright (c) 2011 Savignac, Dinan and Cryan. This is an open-access article subject to a non-exclusive license between the authors and Frontiers Media SA, which permits use, distribution and reproduction in other forums, provided the original authors and source are credited and other Frontiers conditions are complied with. 